Supporting Information for

\title{
Direct Observation of Excimer-Mediated Intramolecular Electron Transfer in a Cofacially Stacked Perylene Bisimide Pair
}

Jooyoung Sung, ${ }^{\dagger}$ Agnieszka Nowak-Król, ${ }^{\not}$ Felix Schlosser, ${ }^{\not}$ Benjamin Fimmel, ${ }^{\not}$ Woojae Kim, ${ }^{+}$Dongho Kim,,$"$ and Frank Würthner, ${ }^{*}$,

${ }^{\dagger}$ Spectroscopy Laboratory for Functional $\pi$-Electronic Systems and Department of Chemistry, Yonsei University, Seoul 120-749, Korea

* Institut für Organische Chemie and Center for Nanosystems Chemistry, Universität Würzburg, Am Hubland, 97074 Würzburg, Germany

\section{Contents}

1. Experimental Details

2. Structure Optimization

3. Spectroscopic Measurements

4. Electrochemical Analysis

5. Estimation of Driving Forces for Intramolecular Electron Transfer

6. NMR Spectra

7. References 


\section{Experimental Details}

General. All reagents were purchased from commercial sources and used as received without further purification, unless otherwise stated. Reagent grade solvents were distilled prior to use. Column chromatography was performed on silica (silica gel, 230-400 mesh). ${ }^{1} \mathrm{H}$ and ${ }^{13} \mathrm{C}$ NMR spectra were recorded on a Bruker Avance 400 spectrometer and calibrated to the residual solvent signals. $J$ values are given in Hz. The following abbreviations were used to designate multiplicities: $\mathrm{s}=$ singlet, $\mathrm{m}=$ multiplet. The high resolution mass spectrum was obtained by electrospray ionization (ESI) and was recorded on an ESI microTOF Focus spectrometer from Bruker Daltonics. The low resolution mass spectrum was obtained by matrix-assisted laser desorption/ionisation (MALDI) and was recorded on an Autoflex II MALDI-TOF mass spectrometer (Bruker Daltonik GmbH).

Compounds. Compounds 1 was reported previously. ${ }^{\mathrm{S} 1}$ and cyclophane PBI-CP was synthesized from perylene-3,4:9,10-tetracarboxylic acid bisanhydride in an analogous way as described recently for a structurally closely related cyclophane bearing tetraphenoxy substituents at the PBI bay positions. ${ }^{\mathrm{S} 2}$ To achieve the highest possible purity, as required to ensure valuable fluorescence results, several regular column chromatographies were followed by recycling gel permeation chromatography (GPC) on a Shimadzu GPC system (LC-20AD prominence pump; SPD-MA20A prominence diode array detector) equipped with three preparative columns (JAIGEL $1 \mathrm{H}+2 \mathrm{H}+2.5 \mathrm{H}$ ) with $\mathrm{CHCl}_{3}$ as eluent at a flow rate of $3.5 \mathrm{~mL} \mathrm{~min}^{-1}$ and a pressure of $20 \mathrm{MPa}$. The synthetic details will be published elsewhere together with a larger series of PBI cyclophane compounds. Additionally, reference compound $\mathbf{S}$ was synthesized to elucidate by cyclic voltammetry the charge transfer ability of the backbone tethering the two PBI units in PBI-CP. This compound was prepared by Glaser-type coupling from terminal alkyne $\mathbf{1}$ in $75 \%$ (Scheme $\mathrm{S} 1)$.

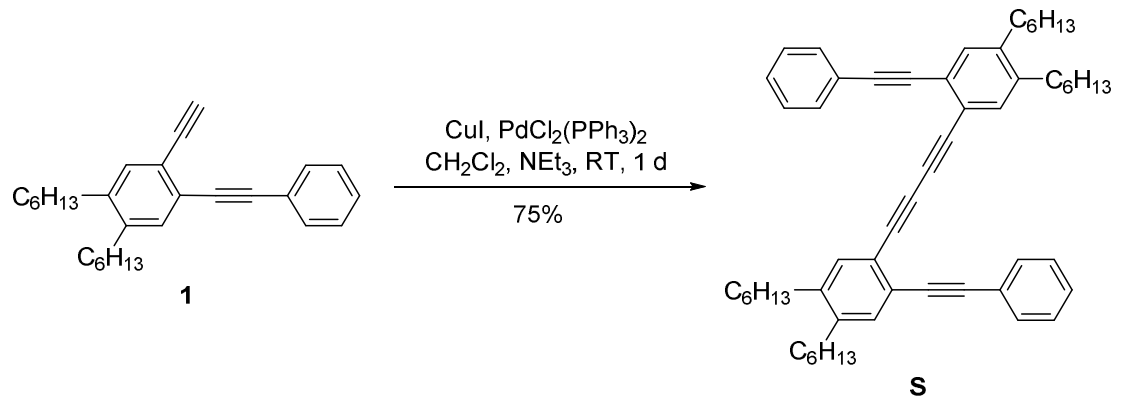

Scheme S1. Synthesis of reference compound S.

Synthesis of compound S. Compound 1 (217 mg, $0.59 \mathrm{mmol})$, bis(triphenylphosphine)palladium(II) dichloride $(21 \mathrm{mg}, 30 \mu \mathrm{mol})$ and copper(I) iodide $56 \mathrm{mg}(0.29 \mathrm{mmol})$ were dissolved in $\mathrm{CH}_{2} \mathrm{Cl}_{2}(4 \mathrm{~mL})$ 
and triethylamine $(4 \mathrm{~mL})$. The reaction mixture was stirred for $1 \mathrm{~d}$ at room temperature. Afterwards, the solution was washed twice with $1 \mathrm{M} \mathrm{HCl}$ solution. Then the organic layer was concentrated under reduced pressure and the crude product was purified by column chromatography (silica, pentane $/ \mathrm{CH}_{2} \mathrm{Cl}_{2}$, 98:2) to afford pure $\mathbf{S}(61 \mathrm{mg})$ and a mixed fraction. Subsequent chromatography of the latter fraction (silica, pentane then pentane/ $\mathrm{CH}_{2} \mathrm{Cl}_{2}, 98: 2$ ) afforded additional portion of $\mathbf{S}$. Both portions were combined to give $\mathbf{S}(161 \mathrm{mg}, 75 \%)$ as an amber-colored solid. UV/Vis $\left(\mathrm{CH}_{2} \mathrm{Cl}_{2}\right): \lambda(\varepsilon)=232(42000), 262.5$ (68000), 285.5 (57200), 296.5 (51000), 340.5 (22900), $370.5 \mathrm{~nm}\left(14900 \mathrm{M}^{-1} \mathrm{~cm}^{-1}\right) .{ }^{1} \mathrm{H}$ NMR (400 MHz, $\left.\mathrm{CD}_{2} \mathrm{Cl}_{2}\right) \delta 7.65-7.53(\mathrm{~m}, 4 \mathrm{H}), 7.39(\mathrm{~s}, 2 \mathrm{H}), 7.37(\mathrm{~s}, 2 \mathrm{H}), 7.34-7.22(\mathrm{~m}, 6 \mathrm{H}), 2.68-2.58(\mathrm{~m}, 8 \mathrm{H}), 1.64-$ $1.55(\mathrm{~m}, 8 \mathrm{H}), 1.47-1.22(\mathrm{~m}, 24 \mathrm{H}), 1.01-0.81 \mathrm{ppm}(\mathrm{m}, 12 \mathrm{H}) .{ }^{13} \mathrm{C} \mathrm{NMR}\left(101 \mathrm{MHz}, \mathrm{CD}_{2} \mathrm{Cl}_{2}\right) \delta 143.4$, 142.2 , 134.0, 132.9, 132.2, 128.93, 128.90, 124.6, 123.7, 122.0, 93.5, 88.6, 82.0, 77.4, 33.1, 32.9, 32.3, 31.40, 31.37, 29.91, 29.87, 23.2, 14.5 ppm. MS LR (MALDI) $\mathrm{m} / z$ calcd for $\mathrm{C}_{56} \mathrm{H}_{66} 738.5 \mathrm{M}^{+}$, found 738.5. MS HR (ESI) $\mathrm{m} / z$ calcd for $\mathrm{C}_{56} \mathrm{H}_{67} 739.5237[\mathrm{M}+\mathrm{H}]^{+}$, found 739.5233. Fluorescence $\left(\mathrm{CH}_{2} \mathrm{Cl}_{2}\right)$ : $\lambda_{\max }=385,414 \mathrm{~nm}$.

\section{Structure Optimization}

DFT calculations were performed for a simplified model compound of PBI-CP (hexyl chains were replaced by methyl groups) by using the B97D3 functional ${ }^{\mathrm{S3}}$ and def2-SVP as basis set ${ }^{\mathrm{S4}}$ implemented in the Gaussian 09 program package. ${ }^{\mathrm{S} 5}$ The structures were geometry optimized (Figure S1), followed by frequency calculations on the optimized structure which confirmed the existence of minimum.

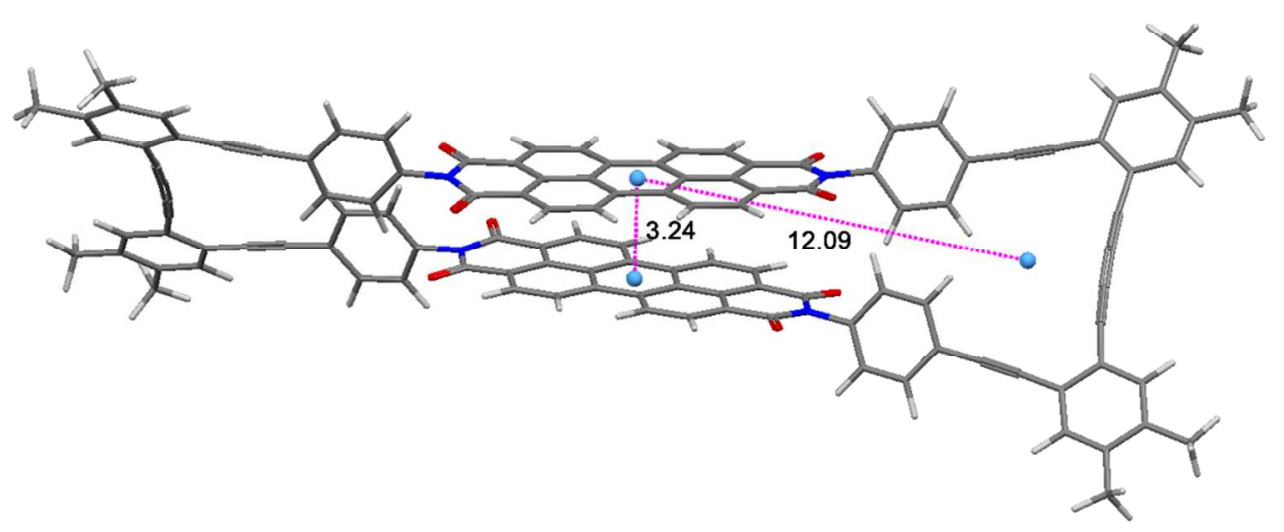

Figure S1. Geometry optimized structure of PBI-CP at B97D3/def2-SVP and the estimated distances, $r_{\mathrm{cc}}$, between the centroids of two PBI moieties or between one PBI unit and one tether unit, used for evaluation of the driving force, $\Delta G^{\circ}$, of the electron transfer process. 


\section{Spectroscopic Measurements}

Steady-State Spectroscopy. Steady-state absorption spectra were recorded on a commercial spectrometer (Cary5000, Varian). Fluorescence spectra were measured by a spectrophotometer (FL2500, Hitachi) and the spectral sensitivity was corrected with the comparison of the well-known chromophores such as rhodamine and coumarin dyes. ${ }^{\mathrm{S} 6}$ The steady-state measurements were carried out by using a quartz cuvette with a path length of $1 \mathrm{~cm}$ at room temperature.

Femtosecond Transient Absorption (fs-TA). The femtosecond transient absorption spectrometer consists of an optical parametric amplifier (OPA; Palitra, Quantronix) pumped by a Ti:sapphire regenerative amplifier system (Integra-C, Quantronix) operating at $1 \mathrm{kHz}$ repetition rate and an optical detection system. The generated OPA pulses have a pulse width of $\sim 100$ fs and an average power of 1 $\mathrm{mW}$ in the range of $280-2700 \mathrm{~nm}$, which are used as pump pulses. White light continuum (WLC) probe pulses were generated using a sapphire window ( $3 \mathrm{~mm}$ thick) by focusing a small portion of the fundamental $800 \mathrm{~nm}$ pulses which was picked off by a quartz plate before entering the OPA. The time delay between pump and probe beams was carefully controlled by making the pump beam travel along a variable optical delay (ILS250, Newport). Intensities of the spectrally dispersed WLC probe pulses are monitored by a High Speed Spectrometer (Ultrafast Systems). To obtain the time-resolved transient absorption difference signal $(\Delta \mathrm{A})$ at a specific time, the pump pulses were chopped at $500 \mathrm{~Hz}$ and absorption spectra intensities were saved alternately with or without pump pulse. Typically, 4000 pulses excite the samples to obtain the fs-TA spectra at each delay time. The polarization angle between pump and probe beam was set at the magic angle $\left(54.7^{\circ}\right)$ using a Glan-laser polarizer with a half wave retarder in order to prevent polarization-dependent signals. Cross-correlation fwhm in pump-probe experiments was less than $200 \mathrm{fs}$ and chirp of WLC probe pulses was measured to be $800 \mathrm{fs}$ in the $400-800 \mathrm{~nm}$ region. To minimize chirp, all reflection optics in the probe beam path and a quartz cell of $2 \mathrm{~mm}$ path length were used.

Femtosecond Broadband Fluorescence Upconversion (BFLUPS). ${ }^{\text {57-10 }}$ A Ti:sapphire laser system (Spectra-Physics, Spitfire) provides $30 \mathrm{fs}, 400 \mu \mathrm{J}$ pulses at $800 \mathrm{~nm}$ with $10 \mathrm{kHz}$ repetition rate. The output beam is divided by a beam splitter with an equivalent ratio. A pulse of $200 \mu \mathrm{J}$ is used to pump an optical parametric amplifier (TOPAS, Light Conversion) which delivers $50 \mathrm{fs}, \sim 40 \mu \mathrm{J}$ gate pulses in the range of 1150-1400 nm with vertical polarization. To achieve the best experimental condition, the wavelength of the gate pulse was selected from 1160 to $1450 \mathrm{~nm}$ depending on the wavelengths of pump pulse and 
fluorescence. The gate beam passes through a periscope, which adjusts the height and rotates the vertically polarized pulse to be horizontally polarized. Then, the gate pulse passes a sequence of SF50 prism $\left(55.5^{\circ}\right)$ compressor with the optimal separation of $12 \mathrm{~cm}$ between the apices of each prism. Finally, the gate beam is relayed onto a nonlinear crystal (Eksma, type II BBO, $\left.\theta 32^{\circ}, \varphi 0^{\circ}, \mathrm{d} 1 \mathrm{~mm}\right)$ by a lens $(f$ $100 \mathrm{~mm}, \mathrm{Tc} 2 \mathrm{~mm}$ ). The pulse energy of the gate beam is attenuated to be kept below $50 \mathrm{~mW}$ by a neutral-density (ND) filter. The rest of the fundamental light is used as a source for a tunable homemade optical parametric amplifier (OPA) system. This homemade OPA system is based on a noncollinearly phase-matching geometry which is easily color-tuned by controlling the optical delay between the white light continuum seed pulses (450-1400 $\mathrm{nm}$ ) produced by using a sapphire window (d $2 \mathrm{~mm})$ and visible pump pulses $(400 \mathrm{~nm})$ generated by frequency-doubling nonlinear crystal (Eksma, type I BBO). The generated visible OPA pulses had a pulse width of $\sim 20 \mathrm{fs}$ and an average power of $35 \mathrm{~mW}$ at $10 \mathrm{kHz}$ repetition rate in the range of $480-700 \mathrm{~nm}$ with vertical polarization. In order to adjust the pulse polarization to prism compressors, the pulse passes through the periscope and then passes through a fused-silica prism compressor $\left(69^{\circ}\right)$, which has the optimal separation of $95 \mathrm{~cm}$. In order to prevent polarization-dependent signals, the pulse polarization is controlled with a half wave plate to be a magic angle $\left(54.7^{\circ}\right)$, and the beam is focused onto a $500-\mu \mathrm{m}$ thick quartz cuvette containing the sample with a lens $(f 300 \mathrm{~mm}$, Tc $2 \mathrm{~mm})$. The pulse energy is attenuated by the ND filter to be kept below $60 \mathrm{~nJ}$. The cuvette was mounted on a motor-driven stage and continuously moved back and forth to avoid photodegradation of the sample and the thermal lens effect. Collection of the fluorescence is achieved by a reflecting microscope objective lens (Newport). Finally, the collected fluorescence is relayed onto the nonlinear crystal by an off-axis parabolic mirror (Newport, $f 50 \mathrm{~mm}$ ). The horizontally polarized upconverted signal is emitted from the type II nonlinear crystal at an angle different from the original fluorescence. Unwanted light of horizontal polarization, coming from the original fluorescence and the pump pulse (or Rayleigh scattered light), is mostly ejected by a wire-grid polarizer (Moxtec PPL04C). The upconverted signals are imaged dispersion-free onto the entrance slit of a spectrograph (Dongwoo Optron, Monora 320i) and then the upconverted spectrum is finally registered with a CCD camera (Andor Technology, DV420 BU). The fwhm of the cross-correlation functions between the scattered pump pulse $(495 \mathrm{~nm})$ and the gate pulse $(1220 \mathrm{~nm})$ is measured to be $100 \mathrm{fs}$. 
Table S1. Photophysical Parameters of PBI-CP in Different Solvents.

\begin{tabular}{ccccc}
\hline Cmpd. & Solvent & $\lambda_{\text {abs }}(\mathrm{nm})$ & $\lambda_{\mathrm{em}}(\mathrm{nm})$ & $\Phi_{\mathrm{fl}}{ }^{b}$ \\
\hline & $\mathrm{THF}$ & $370,462\left(\right.$ sh. $\left.^{a}\right), 492,530$ & 619 & 0.063 \\
\multirow{2}{*}{ PBI-CP } & $\mathrm{CHCl}_{3}$ & $371,464\left(\right.$ sh. $\left.^{a}\right), 494,533$ & $538,593\left(\right.$ sh. $\left.^{a}\right), 615$ & 0.005 \\
& $\mathrm{CH}_{2} \mathrm{Cl}_{2}$ & $371,464\left(\right.$ sh. $\left.^{a}\right), 494,533$ & 543,617 & 0.004 \\
\hline
\end{tabular}

$\overline{{ }^{a} \text { Shoulder peaks. }{ }^{b} \text { Fluorescence quantum yields were measured using rhodamine } 6 \mathrm{G} \text { (in ethanol, } \Phi_{\mathrm{fl}}=0.95 \text { ) as }}$ reference molecule. 
a)
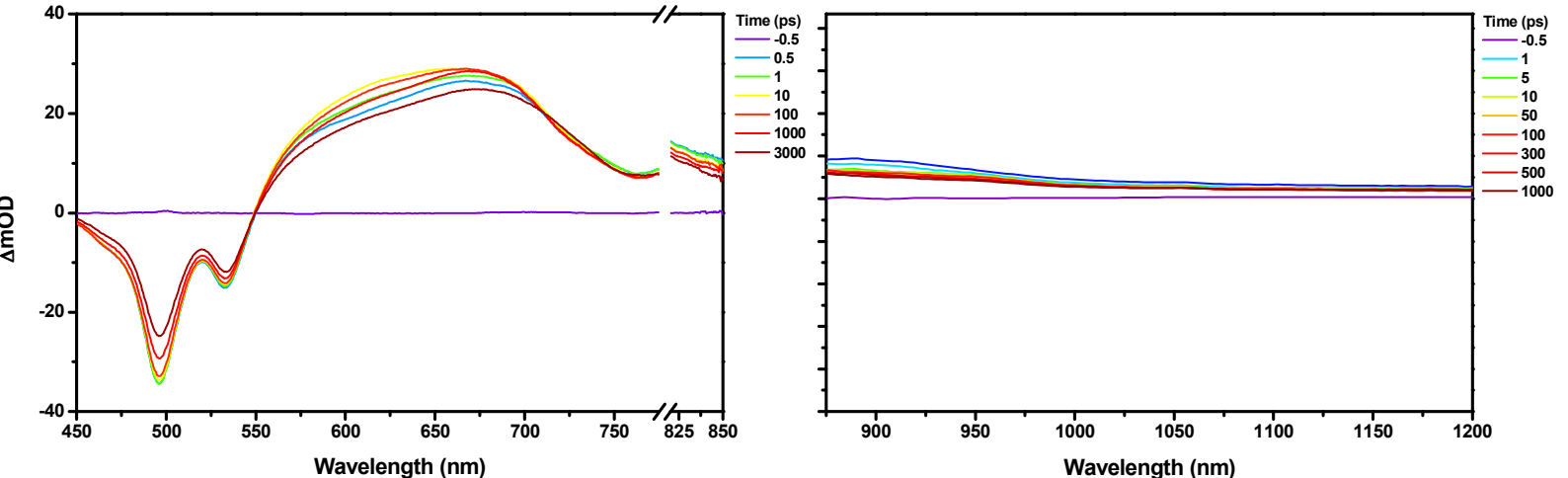

b)
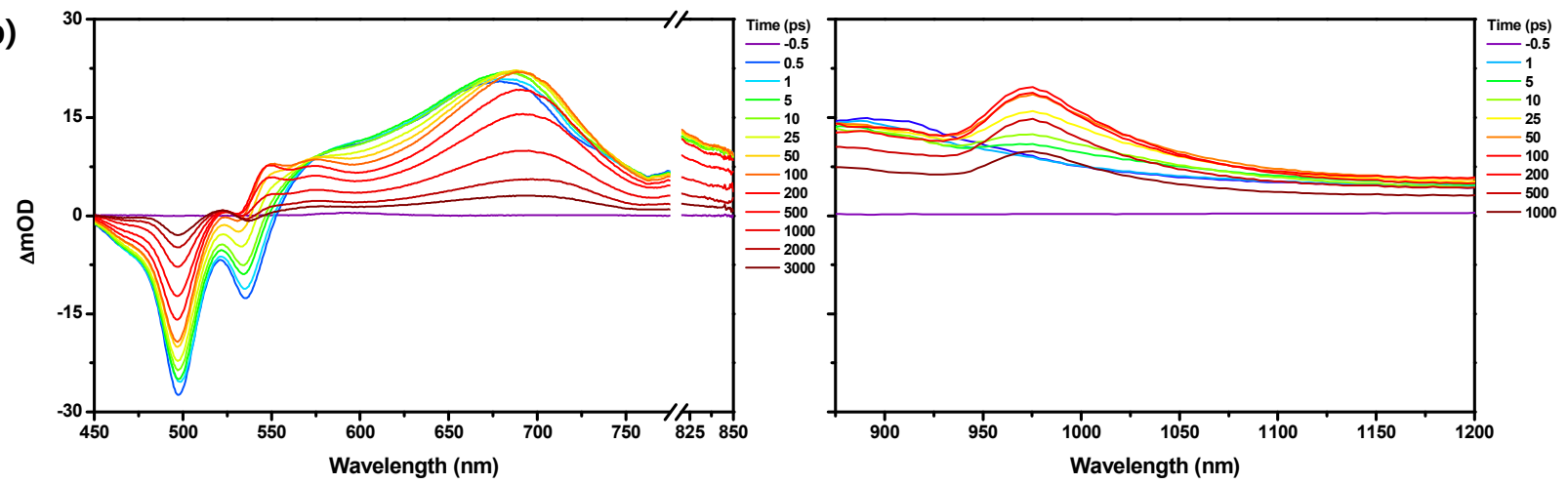

c)
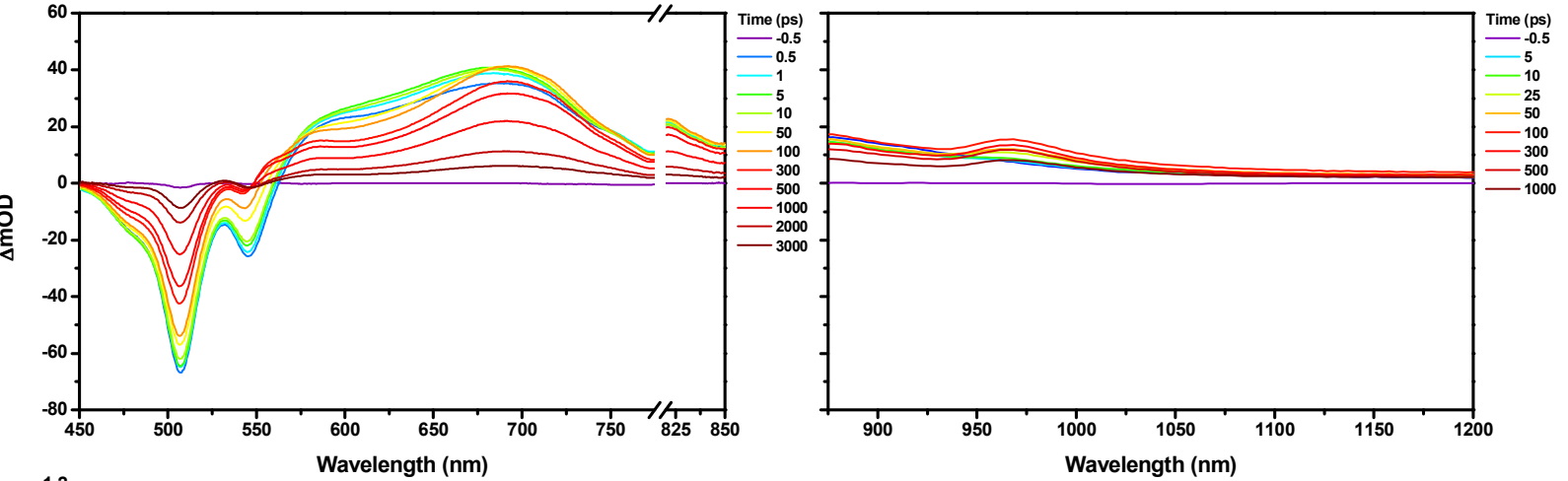

d)
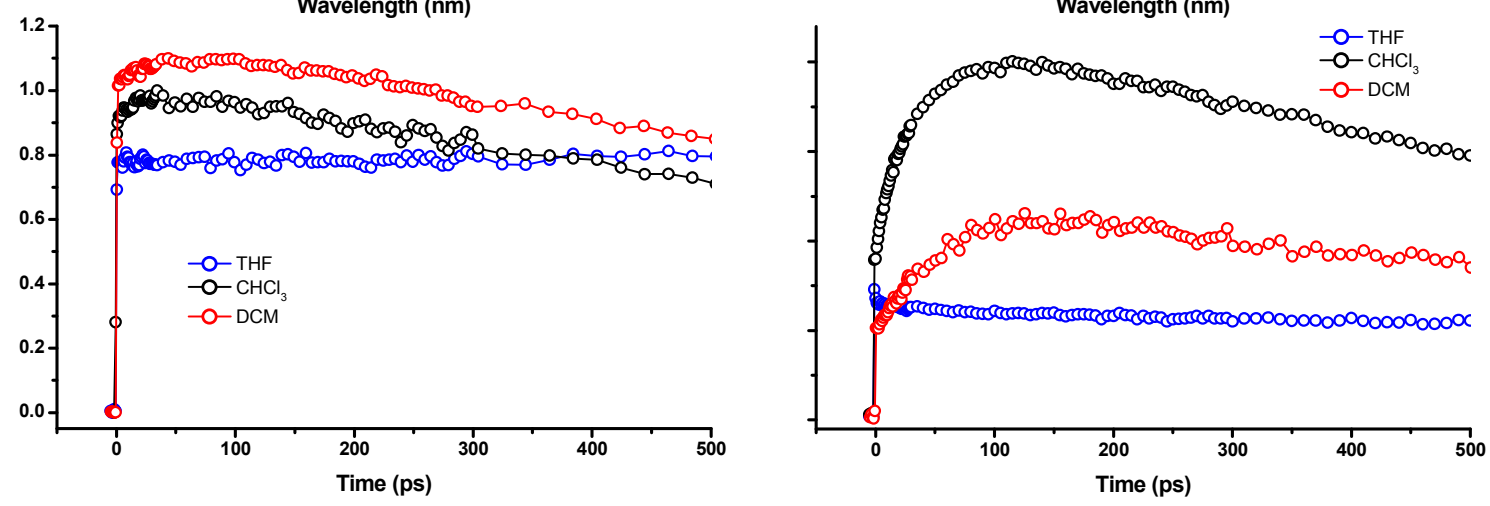

Figure S2. Femtosecond transient absorption spectra of PBI-CP in (a) THF, (b) $\mathrm{CHCl}_{3}$ and (c) DCM obtained by at the photoexcitation at $495 \mathrm{~nm}$. (d) The decay profiles of PBI-CP monitored at 700 (left) and $975 \mathrm{~nm}$ (right), respectively. 


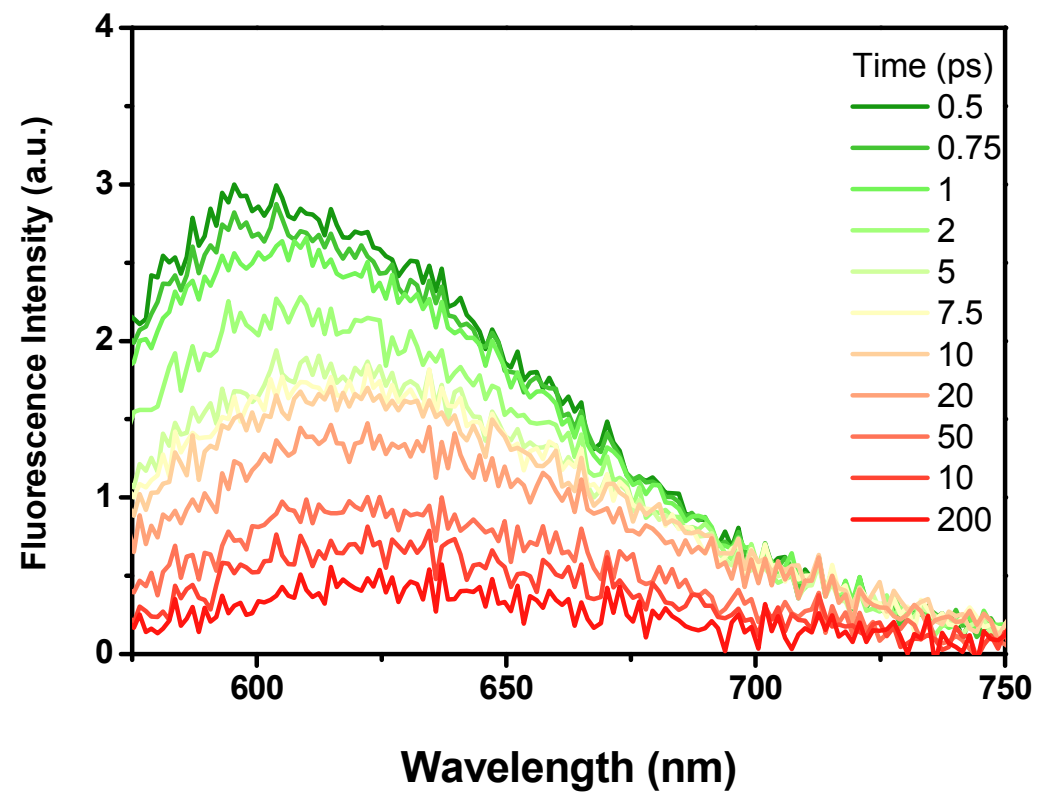

Figure S3. Transient fluorescence spectra of PBI-CP in DCM obtained by the photoexcitation at $495 \mathrm{~nm}$.

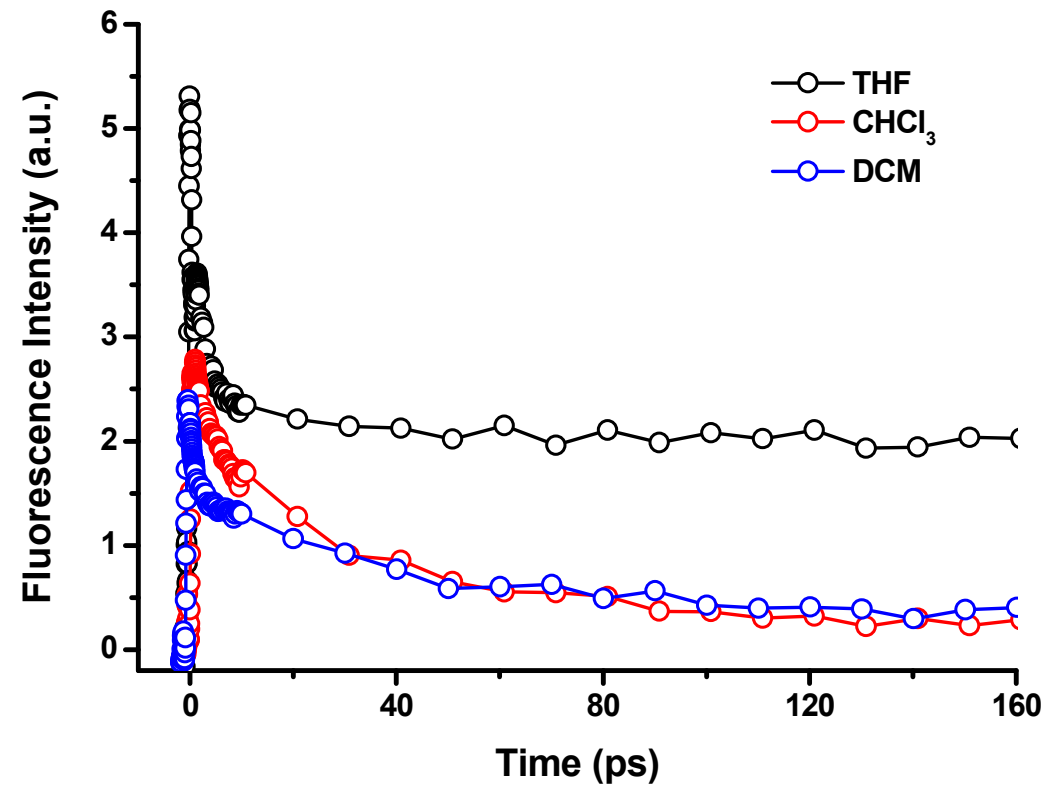

Figure S4. The fluorescence decay profiles of PBI-CP in different solvent monitored at $650 \mathrm{~nm}$ after photoexcitation at $495 \mathrm{~nm}$. 


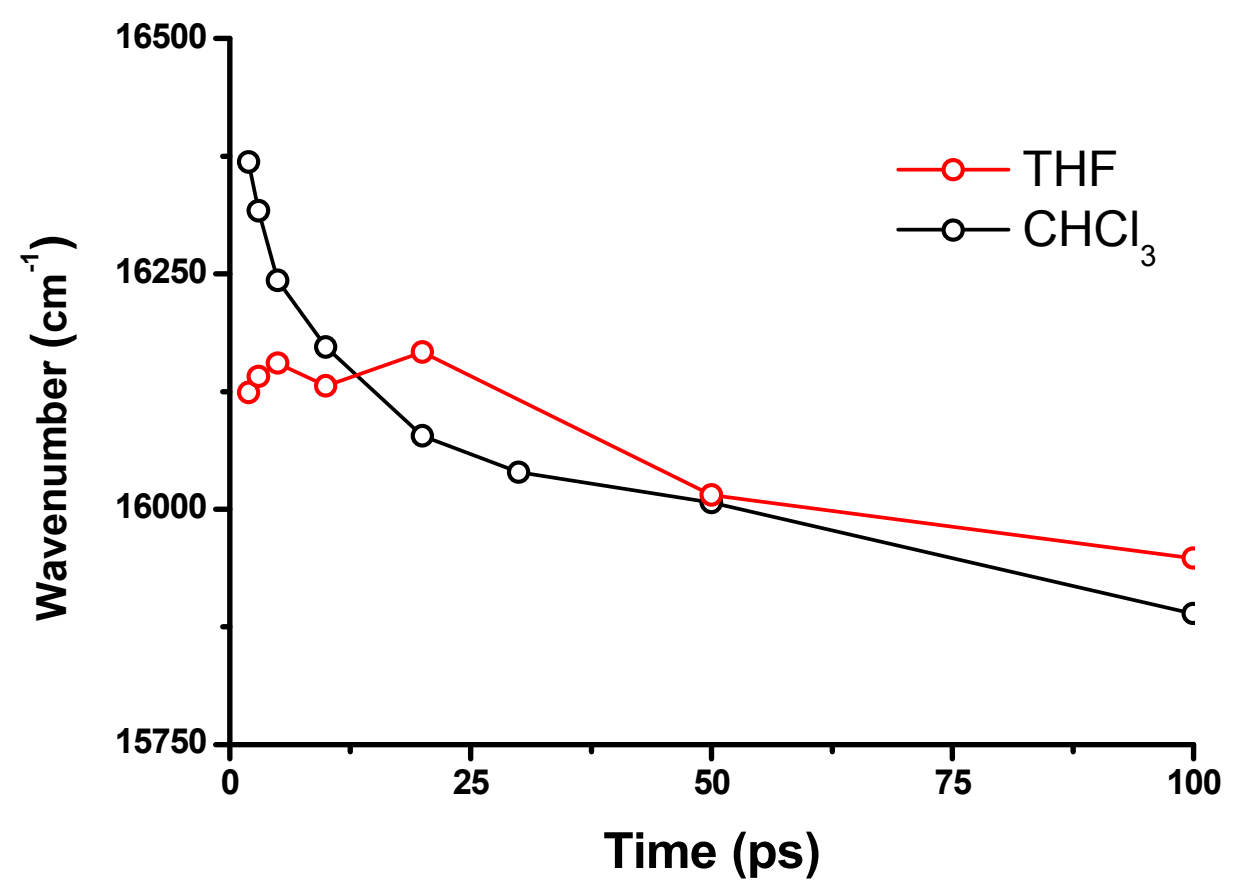

Figure S5. The temporal traces of excimer band of PBI-CP in THF and $\mathrm{CHCl}_{3}$

Table S2. Fitted Parameters of PBI-CP in Different Solvents.

\begin{tabular}{|c|c|c|c|c|}
\hline \multirow{2}{*}{ Methods } & \multirow{2}{*}{$\begin{array}{c}\lambda_{\text {probe }} \\
(\mathrm{nm})\end{array}$} & \multicolumn{3}{|c|}{ Solvents } \\
\hline & & THF & $\mathrm{CHCl}_{3}$ & DCM \\
\hline \multirow{4}{*}{ TA } & 550 & - & $\begin{array}{c}35.8 \text { ps (rise, } 46.8 \%) \\
1.03 \mathrm{~ns}(53.2 \%)\end{array}$ & $\begin{array}{c}75 \text { ps (rise, } 53.1 \%) \\
960 \text { ps }(46.9 \%)\end{array}$ \\
\hline & 600 & $>10 \mathrm{~ns}^{a}$ & $\begin{array}{l}36.1 \mathrm{ps}(37.6 \%) \\
1.09 \mathrm{~ns}(62.4 \%)\end{array}$ & $\begin{array}{c}72 \mathrm{ps}(31.5 \%) \\
1.35 \mathrm{~ns}(68.5 \%)\end{array}$ \\
\hline & 700 & $>10 \mathrm{~ns}^{a}$ & $\begin{array}{c}35.9 \mathrm{ps} \text { (rise, } 7.6 \%) \\
1.07 \mathrm{~ns}(92.4 \%)\end{array}$ & $\begin{array}{c}55 \mathrm{ps}(\text { rise, } 12.9 \%) \\
1.38 \mathrm{~ns}(87.1 \%)\end{array}$ \\
\hline & 970 & $\begin{array}{l}39.6 \mathrm{ps} \\
>5 \mathrm{~ns}^{a}\end{array}$ & $\begin{array}{c}36.4 \mathrm{ps} \text { (rise, } 37 \%) \\
1.18 \mathrm{~ns}(63 \%)\end{array}$ & $\begin{array}{l}60 \mathrm{ps}(\text { rise, } 38.3 \%) \\
1.09 \mathrm{~ns}(61.7 \%)\end{array}$ \\
\hline BFLUPS & 650 & $\begin{array}{c}1.6 \mathrm{ps} \\
>16 \mathrm{~ns}^{a}\end{array}$ & $\begin{array}{c}2 \operatorname{ps}(7.8 \%) \\
33.5 \operatorname{ps}(92.2 \%)\end{array}$ & $\begin{array}{l}1.1 \text { ps }(43.9 \%) \\
46 \text { ps }(56.1 \%)\end{array}$ \\
\hline
\end{tabular}

${ }^{a}$ Too long to be accurately determined in the time windows of our spectroscopic apparatus. 


\section{Electrochemical Analysis}

The CV measurements were performed on a standard, commercial electrochemical analyzer (EC epsilon; BAS Instruments, UK) in a three electrode single-compartment cell under an argon atmosphere. Dichloromethane (HPLC grade) was dried over calcium hydride under an argon atmosphere, distilled, and degassed prior to use. The supporting electrolyte $\mathrm{NBu}_{4} \mathrm{PF}_{6}$ was synthesized according to the literature, ${ }^{\mathrm{S} 6}$ recrystallized from ethanol/water, and dried in a high vacuum. The measurements were carried out under the exclusion of air and moisture at a concentration of $2.5 \times 10^{-4}-1.1 \times 10^{-3} \mathrm{M}$ with ferrocene as an internal standard for the calibration of the potential. Working electrode: Pt disc; reference electrode: $\mathrm{Ag} / \mathrm{AgCl}$; auxiliary electrode: $\mathrm{Pt}$ wire.
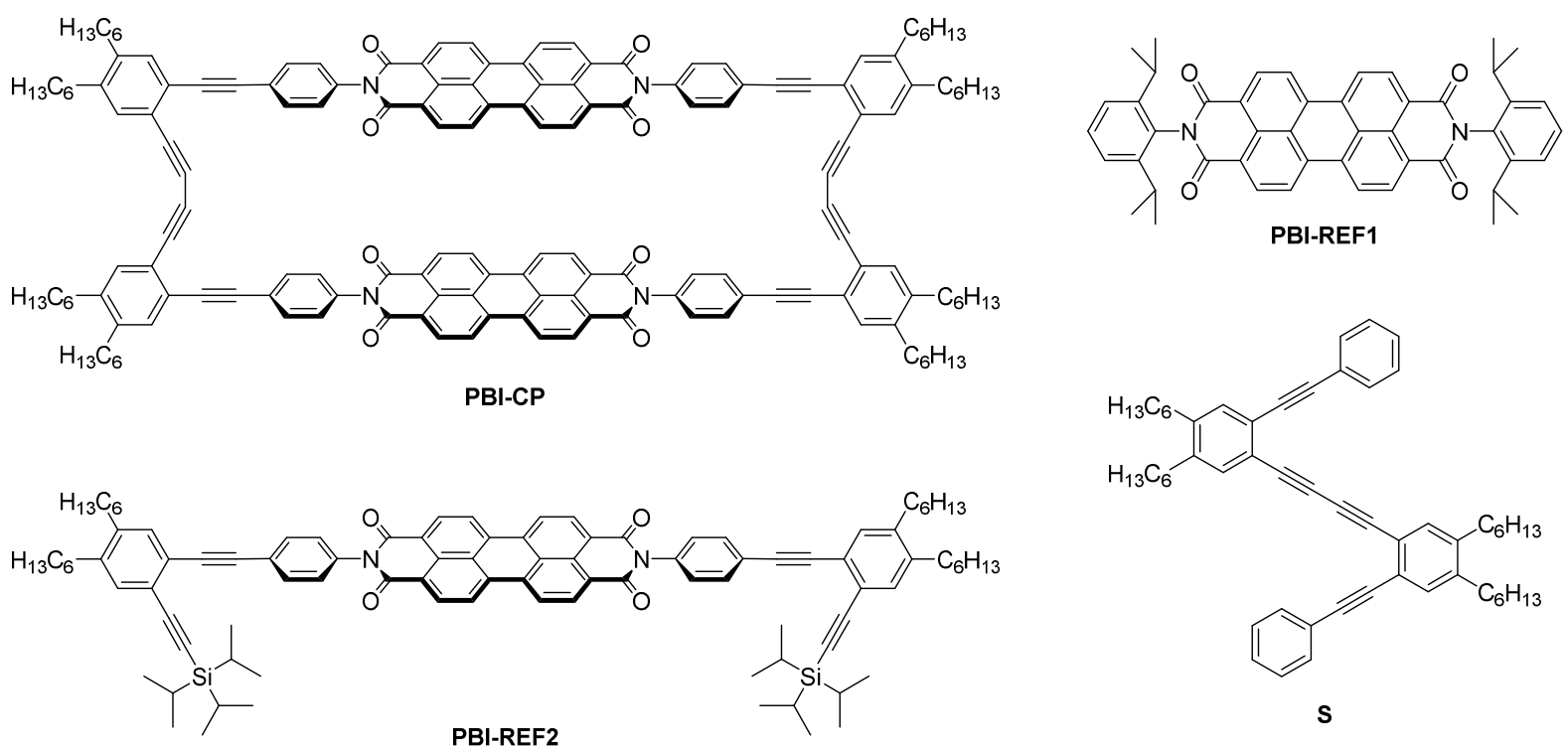

Figure S6. Cyclophane PBI-CP and reference compounds: PBI-REF1, PBI-REF2, and S. 


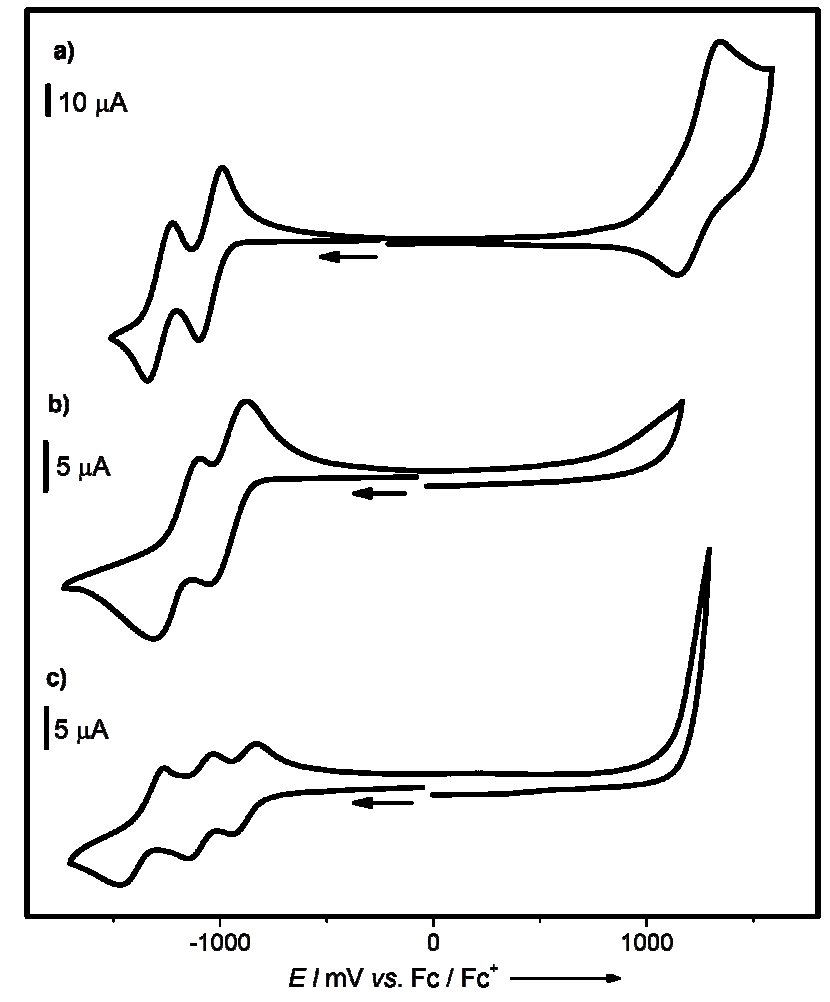

Figure S7. Cyclic voltammogram of a) PBI-REF1 $\left(1.10 \times 10^{-3} \mathrm{M}\right)$, b) PBI-REF2 $\left(3.8 \times 10^{-4} \mathrm{M}\right)$, and c) PBI-CP $\left(2.5 \times 10^{-4} \mathrm{M}\right)$ in $\mathrm{CH}_{2} \mathrm{Cl}_{2}$ solution of $\mathrm{Bu}_{4} \mathrm{NPF}_{6}(0.1 \mathrm{M})$ at a scan rate of $100 \mathrm{mV} \mathrm{s}$. The measurements were calibrated with an internal standard (ferrocene/ferrocenium).

Table S3. Half-Wave Reduction and Oxidation Potentials of PBI-REF1, PBI-REF2, and PBI-CP in DCM. $^{a}$

\begin{tabular}{ccccc}
\hline Cmpd. & $E_{1 / 2}(\operatorname{Red} 3)[\mathrm{V}]$ & $E_{1 / 2}(\operatorname{Red} 2)[\mathrm{V}]$ & $E_{1 / 2}(\operatorname{Red} 1)[\mathrm{V}]$ & $E_{1 / 2}(\mathrm{Ox})[\mathrm{V}]$ \\
\hline PBI-REF1 & - & -1.26 & -1.02 & +1.27 \\
PBI-REF2 & - & -1.20 & -0.96 & - \\
PBI-CP & -1.37 & -1.09 & -0.89 & - \\
\hline
\end{tabular}

${ }^{a}$ Redox potentials $v s$. ferrocene/ferrocenium $\left(\mathrm{Fc} / \mathrm{Fc}^{+}\right)$in $\mathrm{DCM}$ solutions, using $\mathrm{Bu}_{4} \mathrm{NPF}_{6}(0.1 \mathrm{M})$ as a supporting electrolyte at a scan rate of $100 \mathrm{mV} \mathrm{s}^{-1}$. 
(a)
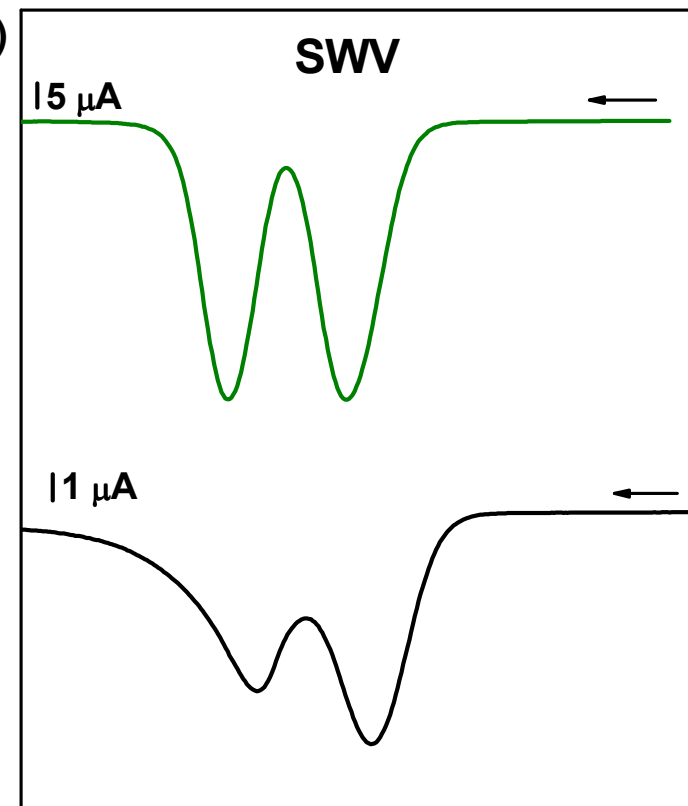

$\mid 1 \mu \mathrm{A}$

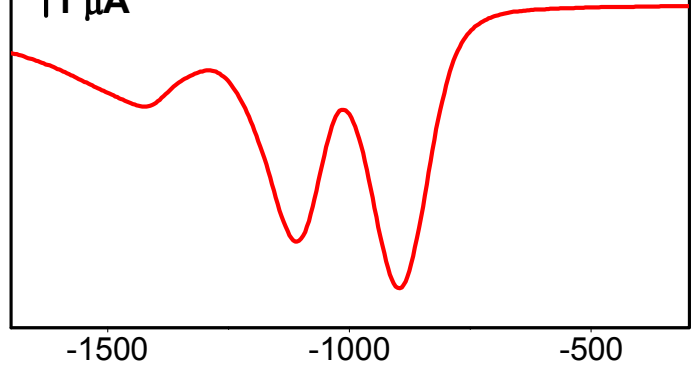

(b)
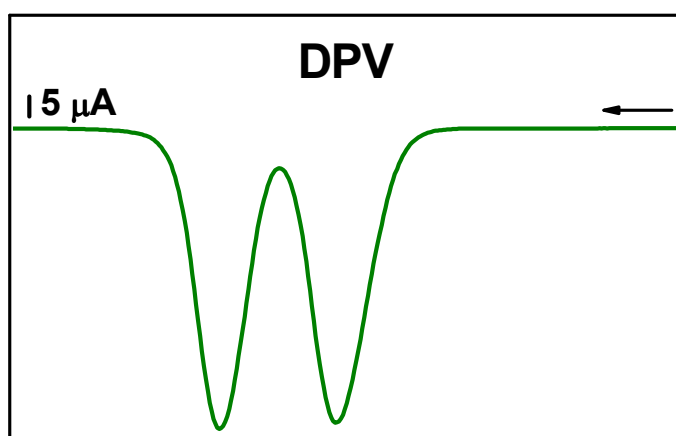

$\mid 1 \mu \mathrm{A}$
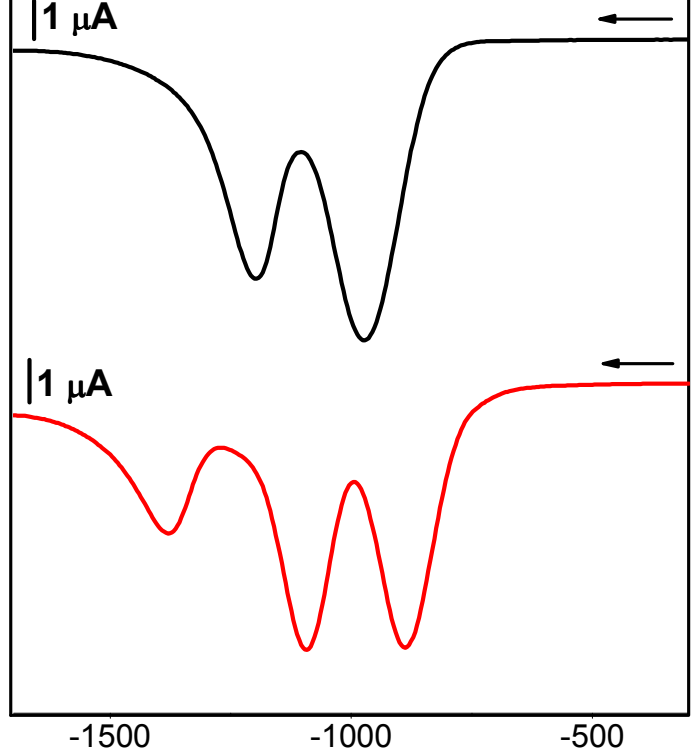

$E / \mathrm{mV}$ vs. $\mathrm{Fc} / \mathrm{Fc}^{+}$

Figure S8. (a) The net current square-wave voltammogram of PBI-REF1 $\left(1.10 \times 10^{-3} \mathrm{M}\right.$, green line), PBI-REF2 $\left(3.8 \times 10^{-4} \mathrm{M}\right.$, black line $)$, and PBI-CP $\left(2.5 \times 10^{-4} \mathrm{M}\right.$, red line $)$ in DCM, supporting electrolyte $\mathrm{Bu}_{4} \mathrm{NPF}_{6}(0.1 \mathrm{M})$, internal reference: ferrocene/ferrocenium, frequency of $15 \mathrm{~Hz}$, amplitude of $25 \mathrm{mV}$, step potential of $4 \mathrm{mV}$; cathodic scan. (b) Differential pulse voltammogram of PBI-REF1 $(1.10 \times$ $10^{-3} \mathrm{M}$, green line), PBI-REF2 $\left(3.8 \times 10^{-4} \mathrm{M}\right.$, black line $)$, and PBI-CP $\left(2.5 \times 10^{-4} \mathrm{M}\right.$, red line $)$ in DCM, supporting electrolyte $\mathrm{Bu}_{4} \mathrm{NPF}_{6}(0.1 \mathrm{M})$, internal reference: ferrocene/ferrocenium, pulse period of 200 $\mathrm{ms}$, pulse width of $50 \mathrm{~ms}$, pulse amplitude of $50 \mathrm{mV}$, step potential of $4 \mathrm{mV}$; cathodic scan. 


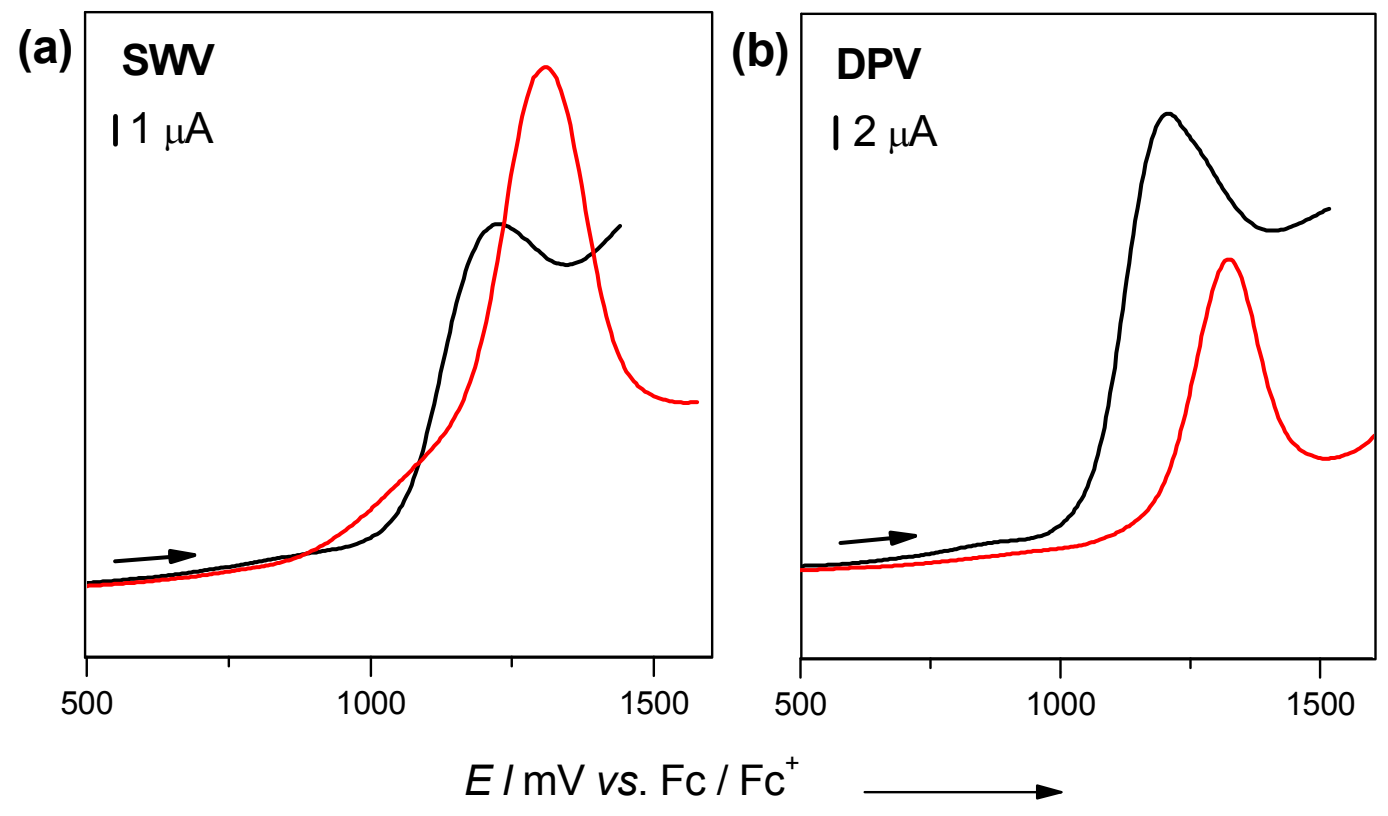

Figure S9. (a) The net current square-wave voltammogram of $\mathbf{S}\left(1.0 \times 10^{-3} \mathrm{M}\right.$, black line $)$ and PBIREF1 $\left(1.1 \times 10^{-3} \mathrm{M}\right.$, red line) in DCM, supporting electrolyte $\mathrm{Bu}_{4} \mathrm{NPF}_{6}(0.1 \mathrm{M})$, internal reference: ferrocene/ferrocenium, frequency of $15 \mathrm{~Hz}$, amplitude of $25 \mathrm{mV}$, step potential of $4 \mathrm{mV}$; anodic scan. (b) Differential pulse voltammogram of $\mathbf{S}\left(1.0 \times 10^{-3} \mathrm{M}\right.$, black line) and PBI-REF1 $\left(1.1 \times 10^{-3} \mathrm{M}\right.$, red line) in $\mathrm{DCM}$, supporting electrolyte $\mathrm{Bu}_{4} \mathrm{NPF}_{6}(0.1 \mathrm{M})$, internal reference: ferrocene/ferrocenium, pulse period of $200 \mathrm{~ms}$, pulse width of $50 \mathrm{~ms}$, pulse amplitude of $50 \mathrm{mV}$, step potential of $4 \mathrm{mV}$; anodic scan.

Table S4. Reduction and Oxidation Potentials of PBI-REF1, PBI-REF2, and PBI-CP, and S Measured in DCM by Square-Wave Voltammetry (SWV) and Differential Pulse Voltammetry (DPV).

\begin{tabular}{cccccc}
\hline Cmpd. & Method & $E(\operatorname{Red} 3)[\mathrm{V}]$ & $E(\operatorname{Red} 2)[\mathrm{V}]$ & $E(\operatorname{Red} 1)[\mathrm{V}]$ & $E(\mathrm{Ox})[\mathrm{V}]$ \\
\hline \multirow{2}{*}{ PBI-REF1 } & SWV & - & -1.27 & -1.02 & +1.32 \\
& DPV & & -1.27 & -1.03 & +1.32 \\
\hline \multirow{2}{*}{ PBI-REF2 } & SWV & - & -1.21 & -0.98 & - \\
& DPV & & -1.20 & -0.97 & - \\
\hline \multirow{5}{*}{ PBI-CP } & SWV & -1.37 & -1.09 & -0.89 & - \\
& DPV & $-1.42($ broad & -1.11 & -0.90 & - \\
\hline \multirow{2}{*}{ S } & SWV & - & - & - & +1.23 \\
& DPV & - & - & - & +1.21 \\
\hline
\end{tabular}

${ }^{a}$ Redox potentials $v s$. ferrocene/ferrocenium $\left(\mathrm{Fc} / \mathrm{Fc}^{+}\right)$in DCM solutions, using $\mathrm{Bu}_{4} \mathrm{NPF}_{6}(0.1 \mathrm{M})$ as a supporting electrolyte. 


\section{Estimation of Driving Forces for Intramolecular Electron Transfer}

There are two possible pathways for photo-induced electron transfer (PET) in PBI-CP; 1) The electron transfer from an electron-rich backbone to the PBI moiety; 2) The electron transfer between the identical PBI moieties via (solvent-induced) symmetry breaking. To estimate the thermodynamic feasibility of these two pathways in PBI-CP system, we performed a Weller analysis ${ }^{\mathrm{S11-13}}$ by applying equation 1:

$$
\Delta G^{\circ}=e\left[E_{o x}(\text { Donor })-E_{r e d}(\text { Acceptor })\right]-E_{00}-\frac{e^{2}}{4 \pi \varepsilon_{0} \varepsilon_{s} r_{c c}}-\frac{e^{2}}{8 \pi \varepsilon_{0}}\left(\frac{1}{r^{+}}+\frac{1}{r^{-}}\right)\left(\frac{1}{\varepsilon_{r e f}}-\frac{1}{\varepsilon_{s}}\right)
$$

where $E_{\text {ox }}$ represents the value for the first oxidation potential of the donor moiety, $E_{\text {red }}$ denotes the first reduction potential of the acceptor moiety, $E_{00}$ is the energy of the $\mathrm{S}_{0}-\mathrm{S}_{1}$ transition of the fluorophore, $r_{\mathrm{cc}}$ refers to the distance between the centers of the donor and acceptor moieties, $r^{+}$and $r^{-}$represent the effective ionic radii of the donor and acceptor radical cation and anion, respectively, $\varepsilon_{\text {ref }}$ denotes the dielectric constant of the solvent used in electrochemistry, and $\varepsilon_{\mathrm{s}}$ is the dielectric constant of the solvent used for spectroscopic studies.

All the components of PBI-CP, i.e. donor and acceptors, that could take part in the electron transfer process, are covalently linked (Figure 1), giving rise to a relatively rigid structure with the restricted possibility of conformational reorganizations. Under these assumptions, we calculated the driving forces $\Delta G^{\circ}$ for both processes based on equation 1. To evaluate the extent of PET in PBI-CP for both cases, we applied the first reduction potential of PBI-REF1 as an acceptor, as well as the oxidation potentials of the two donors, backbone S and PBI-REF1 (Table S3 and S4). The intersection point $\left(E_{00}\right)$ was obtained from the intersection of the normalized absorption and emission spectra of PBI-REF1 (Figure S9). Distances between centers of the donor and acceptor moieties $\left(r_{c c}\right)$ were calculated based on the geometry optimized structure obtained from DFT calculations (B97D3/def2-SVP), which includes dispersion corrections (Figure S1). All the required measurements were carried out in dichloromethane (DCM). Therefore, the last solvent-related term in equation 1 can be neglected. By using the empirical parameters (a reduction potential of $-1.02 \mathrm{~V}$ for the acceptor PBI, PBI-REF1, (Table S3), oxidation potentials of $+1.23 \mathrm{~V}$ for the donor backbone, S (Table S4) and $+1.27 \mathrm{~V}$ for the donor PBI, PBI-REF1 (Table S3), an intersection point at $530 \mathrm{~nm}(c a .2 .34 \mathrm{eV})$, donor-acceptor distances of $12.09 \AA$ for a backbone-PBI variant and $3.24 \AA$ for a PBI-PBI variant, and permittivity of 8.93 for DCM), the driving forces for both processes were estimated to be $-0.22 \mathrm{eV}$ and $-0.55 \mathrm{eV}$, respectively. Thus, the Weller analysis shows clearly that the PET process between two identical PBIs is energetically favored compared to PET from the backbone to PBI moiety. Thus, ultimately, irrespective of the kinetic pathway (direct or sequential PET process), a $\mathrm{PBI}^{+} \mathrm{PBI}^{-}$charge transfer state should finally originate as the energetically favored charge separated state. It is apparent that due to almost identical oxidation potentials of both backbone and PBI, 
it is the distance that is the key parameter determining the thermodynamic driving force for PET. Based on this estimation PET should be a weakly exergonic process for the backbone-PBI variant, where the distance between donor and acceptor units is rather high (12.09 $\AA$ ). On the contrary, the PBI-PBI distance is much shorter $\left(3.24 \AA\right.$ ), which leads to $\Delta G^{\circ}<-0.5 \mathrm{eV}$. Consequently, the spatial cyclophane arrangement of PBI-CP renders the PET process between two cofacial PBI moieties, positioned in close proximity, more favorable.

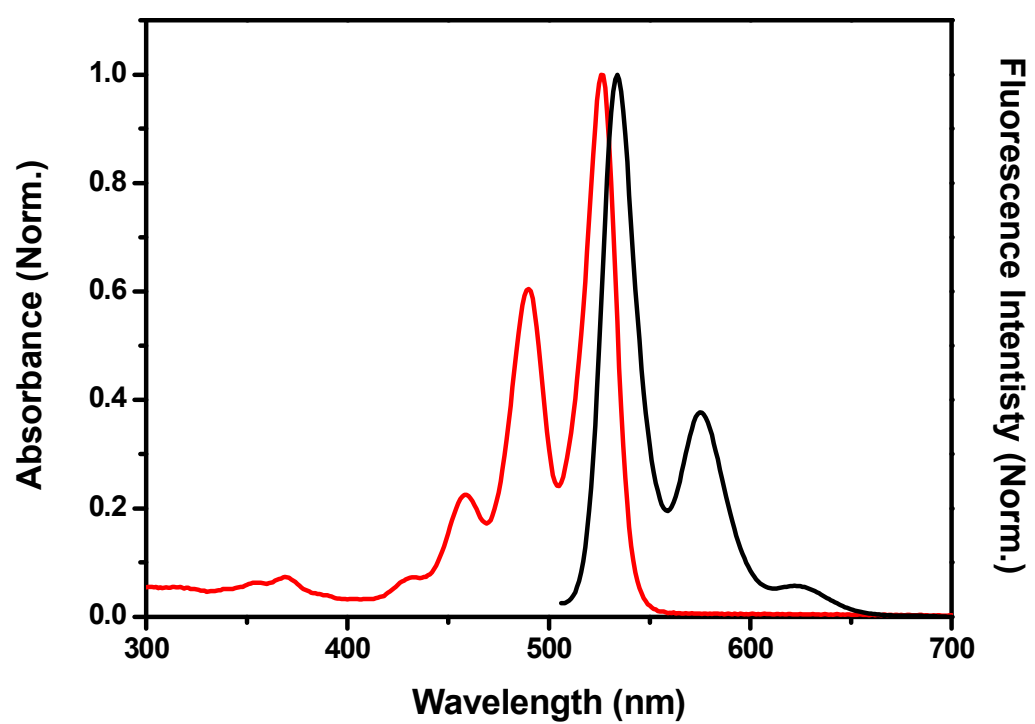

Figure S10. Normalized absorption and emission spectra of PBI-REF1 in DCM. 


\section{NMR Spectra}

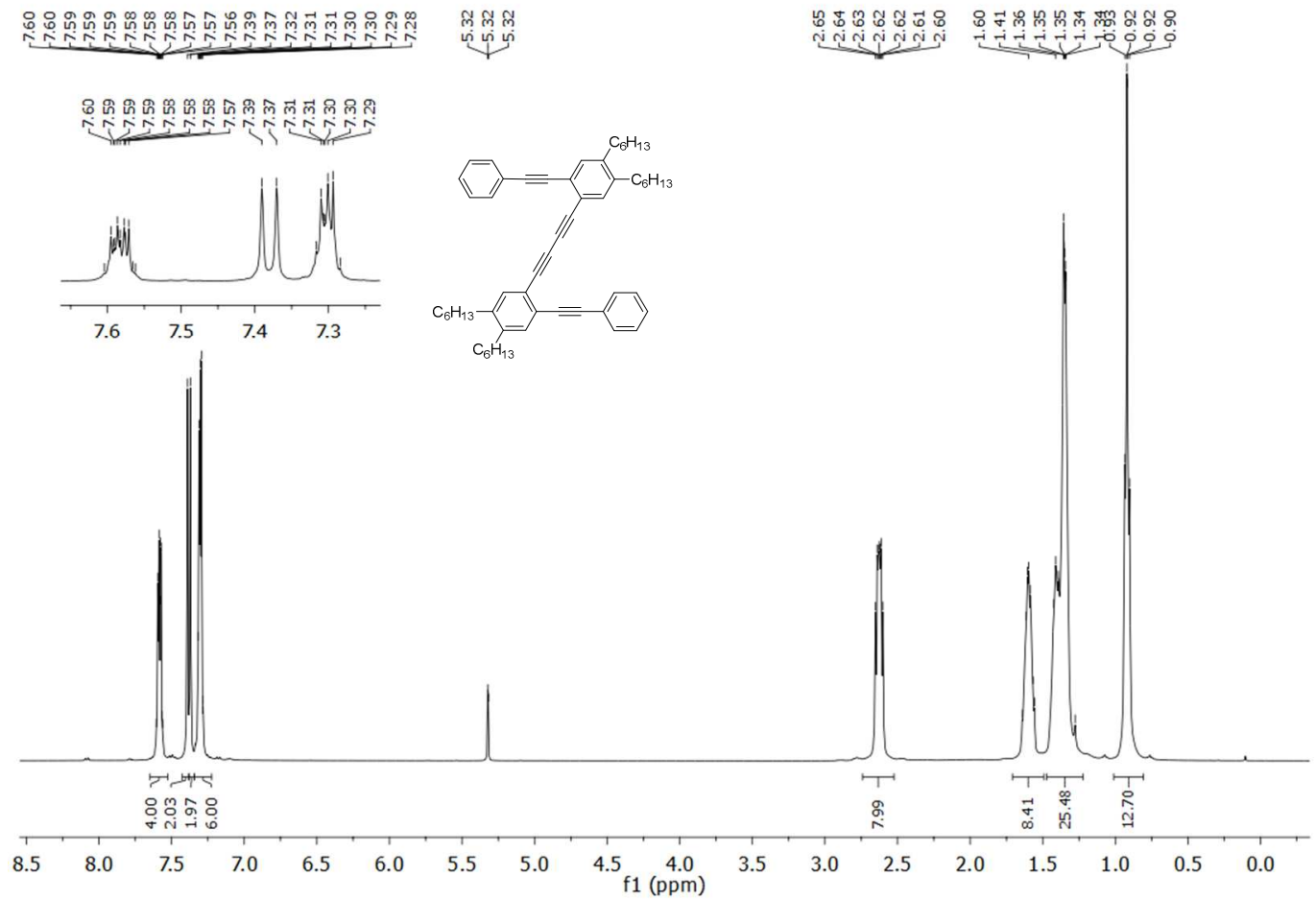

Figure S11. ${ }^{1} \mathrm{H}$ NMR spectrum of $\mathbf{S}\left(400 \mathrm{MHz}, \mathrm{CD}_{2} \mathrm{Cl}_{2}, 25^{\circ} \mathrm{C}\right)$.

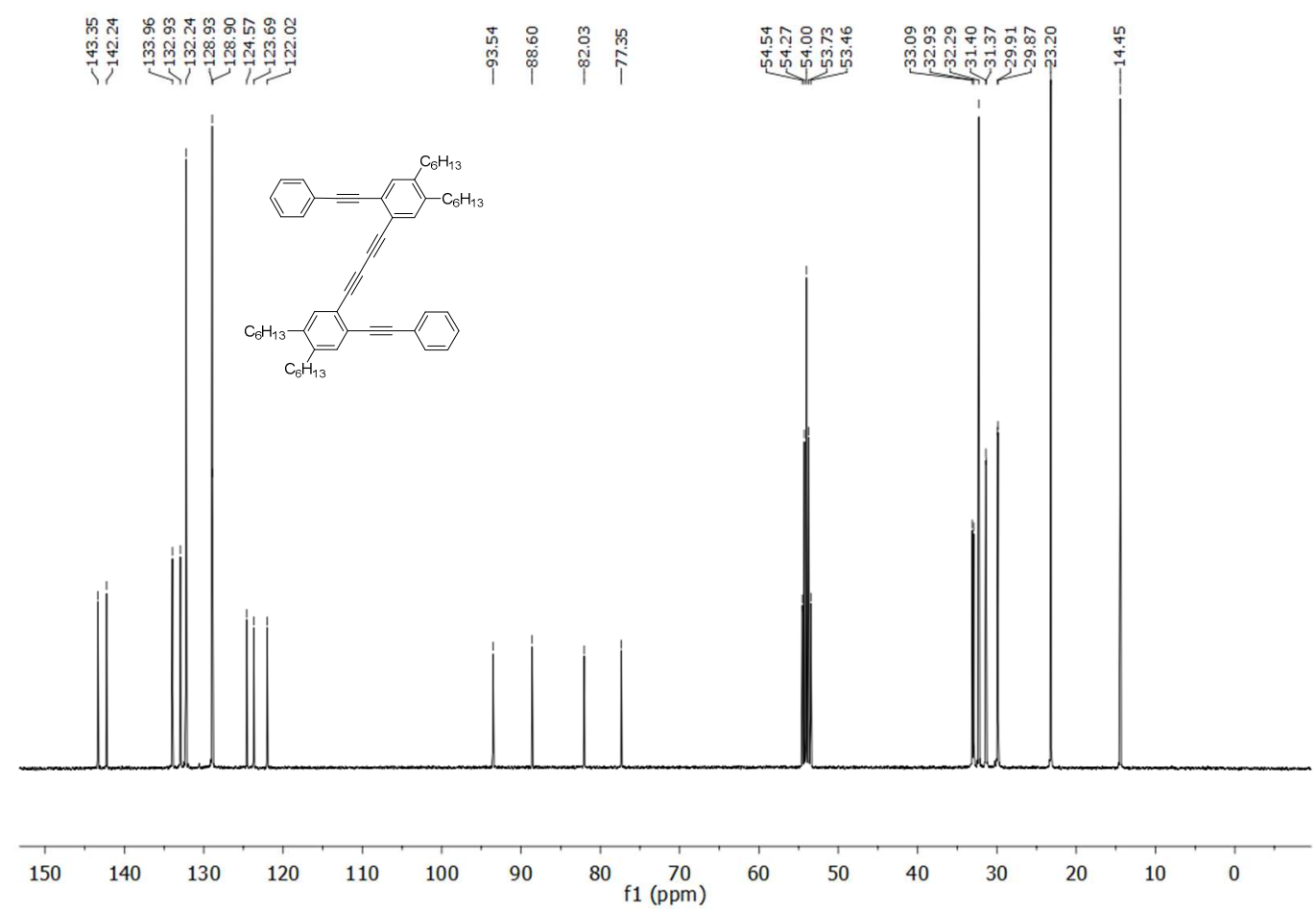

Figure S12. ${ }^{13} \mathrm{C}$ NMR spectrum of $\mathbf{S}\left(101 \mathrm{MHz}, \mathrm{CD}_{2} \mathrm{Cl}_{2}, 25^{\circ} \mathrm{C}\right)$. 


\section{References}

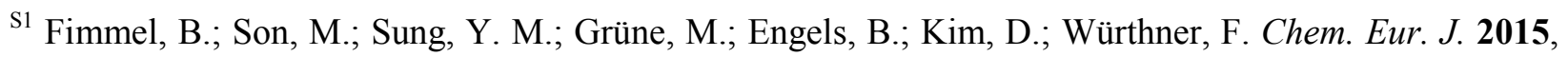
21,615 .

S2 Schlosser, F.; Moos, M.; Lambert, C.; Würthner, F. Adv. Mater. 2013, 25, 410.

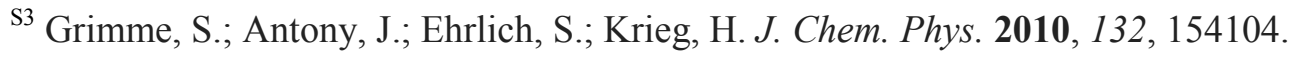

${ }^{\text {S4 }}$ Weigand F.; Ahlrichs, R. Phys. Chem. Chem. Phys. 2005, 7, 3297.

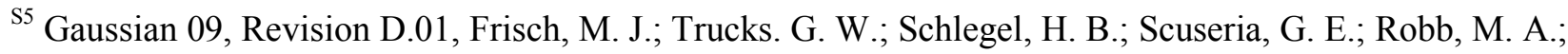
Cheeseman, J. R.; Scalmani, G.; Barone, V.; Mennucci, B.; Petersson, G. A.; Nakatsuji, H.; Caricato, M.; Li, X.; Hratchian, H. P.; Izmaylov, A. F.; Bloino, J.; Zheng, G.; Sonnenberg, J. L.; Hada, M.; Ehara, M.; Toyota, K.; Fukuda, R.; Hasegawa, J.; Ishida, M.; Nakajima, T.; Honda, Y.; Kitao, O.; Nakai, H.; Vreven, T.; Montgomery, J. A.; Peralta, J. E.; Ogliaro, F.; Bearpark, M.; Heyd, J. J.; Brothers, E.; Kudin, K. N.; Staroverov, V. N.; Keith, T.; Kobayashi, R.; Normand, J.; Raghavachari, K.; Rendell, A.; Burant, J. C.; Iyengar, S. S.; Tomasi, J.; Cossi, M.; Rega, N.; Millam, J. M.; Klene, M.; Knox, J. E.; Cross, J. B.; Bakken, V.; Adamo, C.; Jaramillo, J.; Gomperts, R.; Stratmann, R. E.; Yazyev, O.; Austin, A. J.; Cammi, R.; Pomelli, C.; Ochterski, J. W.; Martin, R. L.; Morokuma, K.; Zakrzewski, V. G.; Voth, G. A.; Salvador, P.; Dannenberg, J. J.; Dapprich, S.; Daniels, A. D.; Farkas, O.; Foresman, J. B.; Ortiz, J. V.; Cioslowski, J.; Fox, D. J. Gaussian, Inc., Wallingford CT, 2013.

${ }^{\text {S6 }}$ Lakowicz, J. R. Principles of Fluorescence Spectroscopy; Springer: New York, 2006.

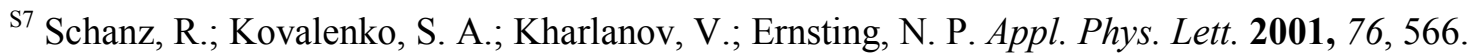

${ }^{\mathrm{S} 8}$ Zhao, L. Lustres, J. L. P.; Farztdinov, V.; Ernsting, N. P. Phys. Chem. Chem. Phys. 2005, 7, 1716.

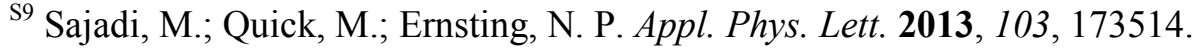

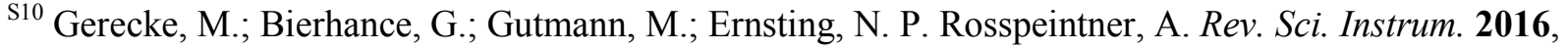
87,053115 .

${ }^{\mathrm{S} 11}$ Fry, A. J. Laboratory Techniques in Electroanalytical Chemistry; Kissinger, P. T.; W. R. Heineman, Marcel Dekker Ltd: New York, 1996.

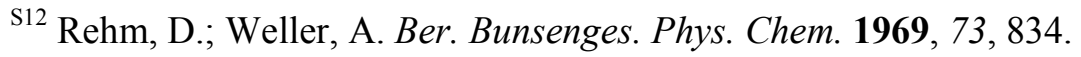

${ }^{\mathrm{S} 13}$ Rehm, D.; Weller, A. Isr. J. Chem., 1970, 8, 259. 